\title{
Improved Approach to the Development of the Crop Monitoring System Based on the Use of Multi-Source Spatial Data
}

\author{
Svitlana Kokhan ${ }^{*}$, Oleksandr Dorozhynskyy², Khrystyna Burshtynska ${ }^{3}$, \\ Anatoliy Vostokov ${ }^{1}$, Oleg Drozdivskyi ${ }^{1}$
}

1 Department of Geoinformatics and Aerospace Research of the Earth, National University of Life and Environmental Sciences of Ukraine, 17 Vasylkivska St., Kyiv, Ukraine

2 Department of Environmental Engineering and Geodesy, University of Life Sciences in Lublin, Leszczyńskiego St. 7, 20-069 Lublin, Poland

3 Department of Photogrammetry and Geoinformatics, Institute of Geodesy, Lviv Polytechnic National University, Lviv, Ukraine

* Corresponding author's e-mail: kokhan_s@nubip.edu.ua

\begin{abstract}
The study describes the stages of conceptual modeling to provide a crop monitoring system based on the multisource spatial data to assess the state of agricultural crops. The process of developing geodatabase models, which is the basis of the crop monitoring system, considered the construction of a set of diagrams of the Unified Modeling Language (UML). The UML Sequence diagrams were developed to describe the specific properties of crop monitoring system components and their behavior. The developed data flow diagram showed the data flow in the crop monitoring system and described the processes involved in the system for the transfer of data from the source files to the geodatabase. The approach presented in the study can be suggested as a methodology that is suitable for a wide range of developers of monitoring systems.
\end{abstract}

Keywords: geodatabase, spatial data, remote sensing, crop monitoring system

\section{INTRODUCTION}

In the modern world, the information about the changes in the crop condition growth during the season needs the integration of multi-source data in one information system. Currently, the conceptual model is a key component of the environmental monitoring systems, which ensures the integration of heterogeneous data between crop state indicators and remote sensing data. The approach of conceptual modeling allows designing a model, which is a tool for structuring data and at the same time, it is software-independent. A conceptual model provides an integration of system dynamics, as well as shows interactions and connections between the crop characteristics.

In implementing monitoring systems, the starting point should be developing a conceptual model of a system. The process of designing a conceptual model expresses the origin of a problem as well as peculiarities of an object or a study area. Because agricultural crops have spatial and temporal characteristics, the conceptual model would be expected to possess the spatial and temporal schemes [Leroux et al. 2019].

Multi-source spatial datasets are mainly used in agricultural practices in order to provide the crop growth monitoring. Remote sensing data, being the source of actual spatial information both for farming and precision agriculture, requires different pre-processing and thematic processing techniques to be used in order to obtain comparable information that would be integrated into the crop monitoring systems [Rekha et al. 2018, Habibie et al. 2018, Weiss et al. 2020].

Satellite and air-born remote sensing can significantly contribute to providing repeatable information with different spatial, spectral and 
temporal resolutions over a large area. The following applications of remote sensing data in agriculture are mainly reported: crop state monitoring, drought/water stress monitoring; yield estimation; crop acreage determination; cropland mapping; mapping of land use/land cover changes; precision agriculture and irrigation management [Atzberger 2013]. Satellite remote sensing and application of multicriteria analysis for maize cultivation were described in [Habibie et al. 2018]. An overview of remote sensing and proximal sensing data in agriculture was presented by M. Weiss [Weiss et al. 2020] for various scales and a large range of stakeholders.

Satellite monitoring is applicable for the evaluation of the vegetation dynamics based on the relevant vegetation indices for a certain period and providing the access to the crop rotation data of the field and of the given crop. The relevant information on the current stage of crop growth and development is also widely monitored.

Remote sensing based on Unmanned Aerial Vehicle (UAV) data has also been proven to be an efficient tool and it is widely applied in rapid and non-destructive estimation of crop status, leaf $\mathrm{N}$ content and LAI evaluation [Hyun et al. 2013, Quemada et al. 2020]. The study of Gonzalo Cucho-Padin et al. [Cucho-Padin et al. 2019] showed the developing Open-Software tools for the analysis of the vegetation parameters based on the UAV images.

Since crops have diverse temporal characteristics, the conceptual model should include the spatial and temporal patterns. The heterogeneous data obtained from different observations cannot be directly compared because they have not been collected under the same set of acquisition conditions, e.g. within the same time period, with consistent sensors or under similar management practices [Leroux et al. 2019]. Thus, all input data should be unified and it is known to be rather complex task. It demands a wide range of scientific approaches to be applied for the constructing environmental modeling structures [Argent 2004]. Moreover, the development of domainspecific software structures is a complex task, in which it is necessary to take advantage of the modern software development process. In addition, there is a need to take into account the fact that the developers should be specialists in agricultural production, data processing specialists in remote sensing, GIS specialists and software engineers [Argent 2004].

Thus, the conceptual model is the most expedient tool to develop a diagram based on UML. The Unified Modeling Language (UML) is a software standard modeling language for visualizing, specifying, constructing and documenting elements of systems, and at that time software systems are complex systems consisting of cooperating heterogeneous software, hardware and database subsystems, trading and distribution of agricultural products. The UML is used for the documentation and the describing the functionalities provided by the system and their associated interactions.

Designing models of systems based on UML diagrams was considered in papers [Khaiter and Erechtchoukova 2019, de Kinderen and Kaczmarek-He $\beta$ 2019]. Khaiter and Erechtchoukova presented a formalized approach to the entire process of software development and design in the area of sustainable decision-making on the basis of ecosystem services with using methodology on the application of the UML. De Kinderen et al. demonstrated the application of multi-level, integrated modeling and programming to model organizational structures which allows overcoming some limitations to modeling approaches situations.

Decision Support System which is able to assist farmers to make proper decisions is presented in the paper [Zhai et al. 2020]. It is described the use of UML for modeling data in order to obtain the desired information to increase the agricultural productivity by receiving the weather information through a decision support system.

UML sequence diagrams provide valuable information for comprehension, debugging, maintenance, and software archeology. In the study [Alvin et al. 2019] presented a framework for static generation of UML sequence diagrams from object-oriented source code, which provides a query refinement system to guide the interactions in the source code. The proposed technique involves constructing a hypergraph representation of the source code, traversing the hypergraph with respect to a user-defined query, and generating the corresponding set of sequence diagrams. This technique implemented framework as a tool, StaticGen (supporting software: StaticGen).

The study [Jetlund et al. 2019] aimed to improve the implementation of geospatial models in Web Ontology Language (OWL). The 
methods and rules for the conversion of the geospatial information from UML models to implementation as OWL Ontologies were presented in the paper.

In the study [Sadowska and Huzar 2019] the rules for conversion and verification of UML class diagrams to their OWL 2 representation were reviewed. The extent to which state-ofthe-art transformation rules cover the semantics expressed in class diagrams was presented. New transformation rules showing the semantics not yet covered but expected from the point of view of domain modeling pragmatics were determined. The transformations proposed in the study can be used for automatic validation of compliance of UML class diagrams with respect to OWL 2 domain ontologies.

In the paper [Filipova and Nikiforova 2019] defined more than 20 rules, which should be followed while creating use case diagrams to make them more efficient to visualize and understand. The requirements of the use case diagrams and placement criteria were also examined, which served as a basis for the creation of an automatic use case diagram layout algorithm.

\section{STATEMENT OF PROBLEM}

Many developed techniques usually take into account one data source in order to provide crop monitoring and evaluation of the crop state. These are mainly the satellite remote sensing data and ground-based data, or air-born data with groundbased information. The problems of structuring spatio-temporal multi-source data for assessing the state of crops that provide a convenient and user-friendly display of data being the basis of the monitoring system, are not sufficiently considered in previous studies.

In order to increase the efficiency of the crop monitoring system and to provide the appropriate information support of farmers, the presented multi-level approach includes the stages of conceptual modeling to develop the crop monitoring system for assessing the state of crops, is given in the paper.

The aim of the study was to describe the process of the development of geodatabase models in order to provide the crop monitoring system. During the study, the following tasks were solved: to develop the models of the crop geoinformation system based on UML and to describe the structure of the geodatabase of the crop monitoring system.

\section{RESEARCH METHODOLOGY}

The approach based on the Unified Modeling Language (UML) was used when developing the models of the geoinformation crop monitoring system. The UML approach provides the combination of static structure elements with dynamic properties [Khaiter and Erechtchoukova 2019], expands the possible applications of geodatabases.

The unified modeling language UML identifies key stakeholders and considers their participation goals. Using three groups of graphical models (functional, object, and dynamic), UML provides a description of various aspects of development of the crop monitoring system.

The developed multi-level approach included the stages of conceptual modeling in order to provide the crop monitoring system based on multisource spatial data for assessing the state of crops.

A conceptual modeling expresses the most significant features of the real processes and phenomena providing the possibility to take into account the logical representation of the data structure and the support for all representations of users being the basis for the further design of the developed system.

UML diagrams are the diagrams based on the Unified Modeling Language with the purpose of visually representing a system. The two broadest categories of UML diagrams are Behavioral and Structural UML diagrams. Some UML diagrams describe the structure of a system, and other express the system's behavior. The crop monitoring system is described firstly by the behavior of its building components, which have different origin, spatial, temporal and spectral properties. In order to properly describe the crop monitoring system which includes multi-source data, a set of Sequence diagrams were used in the study.

The crop rotation, which is located at the University's Experimental Station in northern ForestSteppe of Ukraine in Kyiv region, was used as test site in the study (Figure 1). 


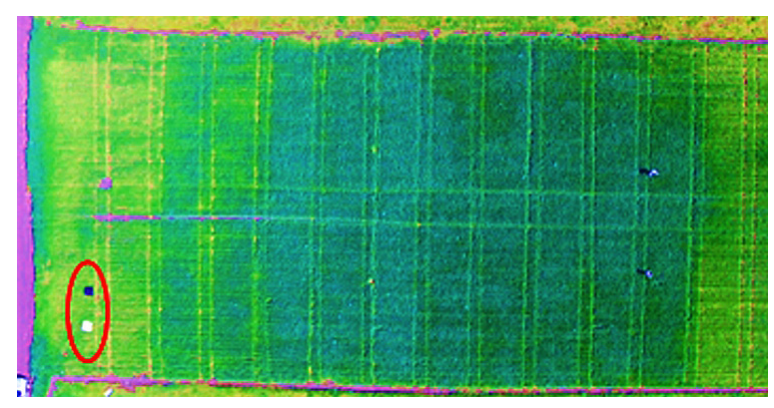

Figure 1. The University's Experimental Station

\section{RESULTS AND DISCUSSION}

The development of a conceptual model of crop monitoring system is carried out by constructing a set of UML diagrams. Taking into account the specific features of the components of crop monitoring system and in order to explain interactions between them, the UML Sequence diagrams were designed in the study.

The general sequence of obtaining data to provide crop monitoring, including the spatialtemporal characteristics of crops, the necessary and sufficient amount of remote sensing data, ground-based and laboratory measurements, is shown in Figure 2.

The spectral characteristics of crops, obtained both in-situ and those based on satellite and airborn imagery, biometric and biophysical parameters of vegetation measured under field conditions, are incorporated into geospatial database. These data are used for modeling crop state. For validation and verification of models, field measurements were conducted in crop rotation on chernozem soils. Thus, the diagram reflects the general sequence of obtaining spatial and nonspatial data for the crop monitoring system in a compact form.

The next stage of modeling is the development of sequence diagram, which describes the process of obtaining remote sensing data, including satellite data of medium and high spatial resolution, air-born imagery, and determines the necessary and sufficient amount of remote sensing data to provide crop monitoring. The metadata analysis involves the application of free satellite imagery sources. In order to request commercial satellite imagery, the product level, period of image acquisition, cloud cover (\%), satellite viewing angle are indicated as well as the area of interest.

The period of data acquisition, camera type, flight altitude and image spatial resolution are requested to order the air-born imagery. Quasisynchronous measurements in-situ based on GreenSeeker active sensor are important components of the system (Figure 3). The GreenSeeker NDVI values were used for calibration and verification of satellite and air-born data. The NDVI values were measured at a certain location with known coordinates. The adjusted ground vegitation index (VI) are applicable in modeling time series data for crop monitoring. The next stage includes the provider selection of remote sensing data and the availability of software for preprocessing of different data formats and their thematic processing (Figure 4).

Advanced remote sensing technologies continue to broaden the capabilities of satellite

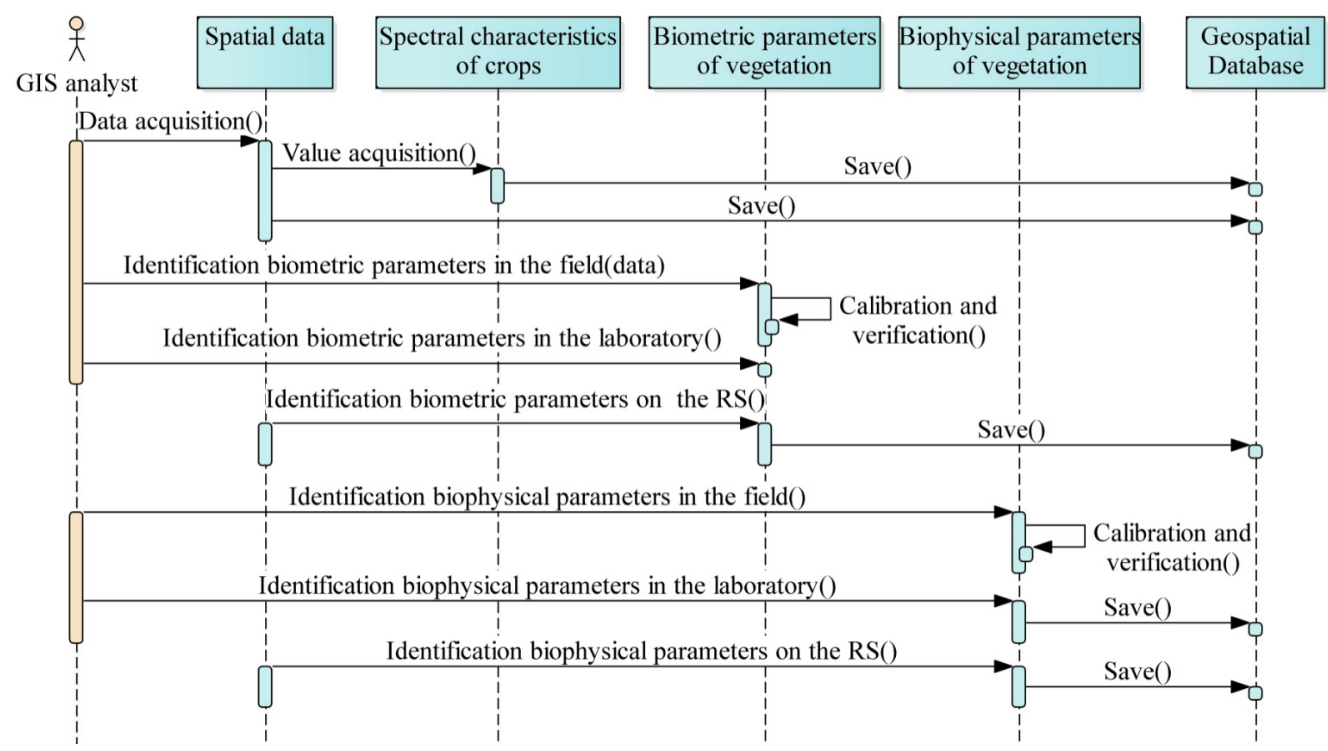

Figure 2. The general sequence of obtaining spatial and non-spatial data 


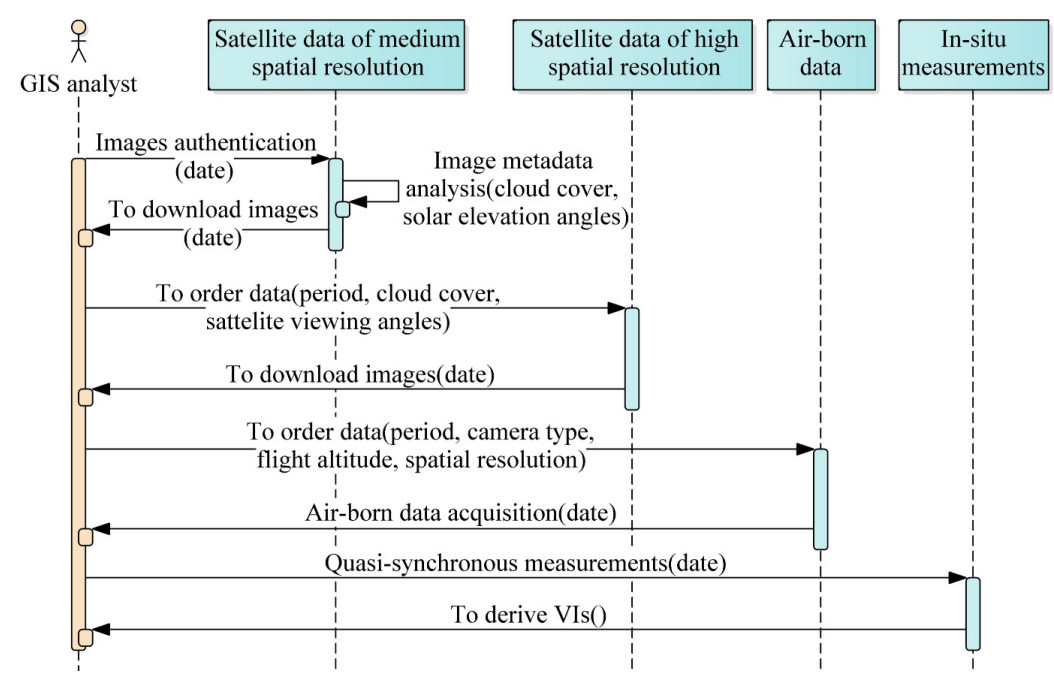

Figure 3. Remote sensing data collection

imaging, providing more types of data at a different scale.

Space, air-born and ground segments are designed to collect, process and provide information in a proper time. The space segment ensures the ability to collect data based on different spatial, temporal, spectral and radiometric resolution. The air-born segment enables receiving data within test sites and the ground segment ensures data collection for calibration and verification of remote sensing data.

Using the specific techniques of remote sensing data pre-processing and thematic processing is one of the important tasks of this stage. For satellite images, geometric correction is carried out on a pixel-by-pixel basis. Atmospheric correction is an obligatory process. On the basis of the UAV data, orthophotos are created for each spectral channel. Sub-pixel geometric correction of the imagery obtained at a different date is performed based on a certain orthophoto with maximal spatial resolution [Stankevich et al. 2018]. The test points for the GreenSeeker ground measurements as well as the plant sampling for chemical analysis are the same. The above-mentioned techniques have been also applied in the study of the crop state monitoring [Kokhan and Vostokov 2020].

The next important stage in creating a model of the crop monitoring system is to develop a Data Flow diagram (DFD). The DFD allows creating a flow of data in an information system and describes the processes that are involved in a system to transfer data from the source files to the storage files and generation of reports. A DFD for the crop monitoring system is presented in Figure 5.

UML is successfully used to develop complex software and business project systems. It is also applied in the modelling of the ISO 19100 series

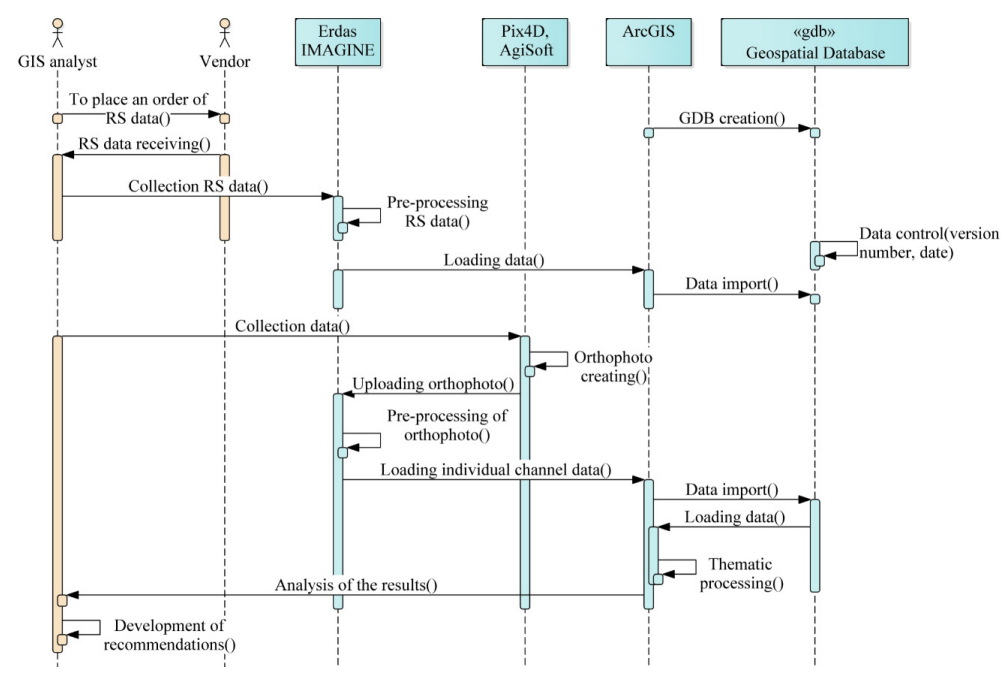

Figure 4. Remote sensing data providers and data processing 


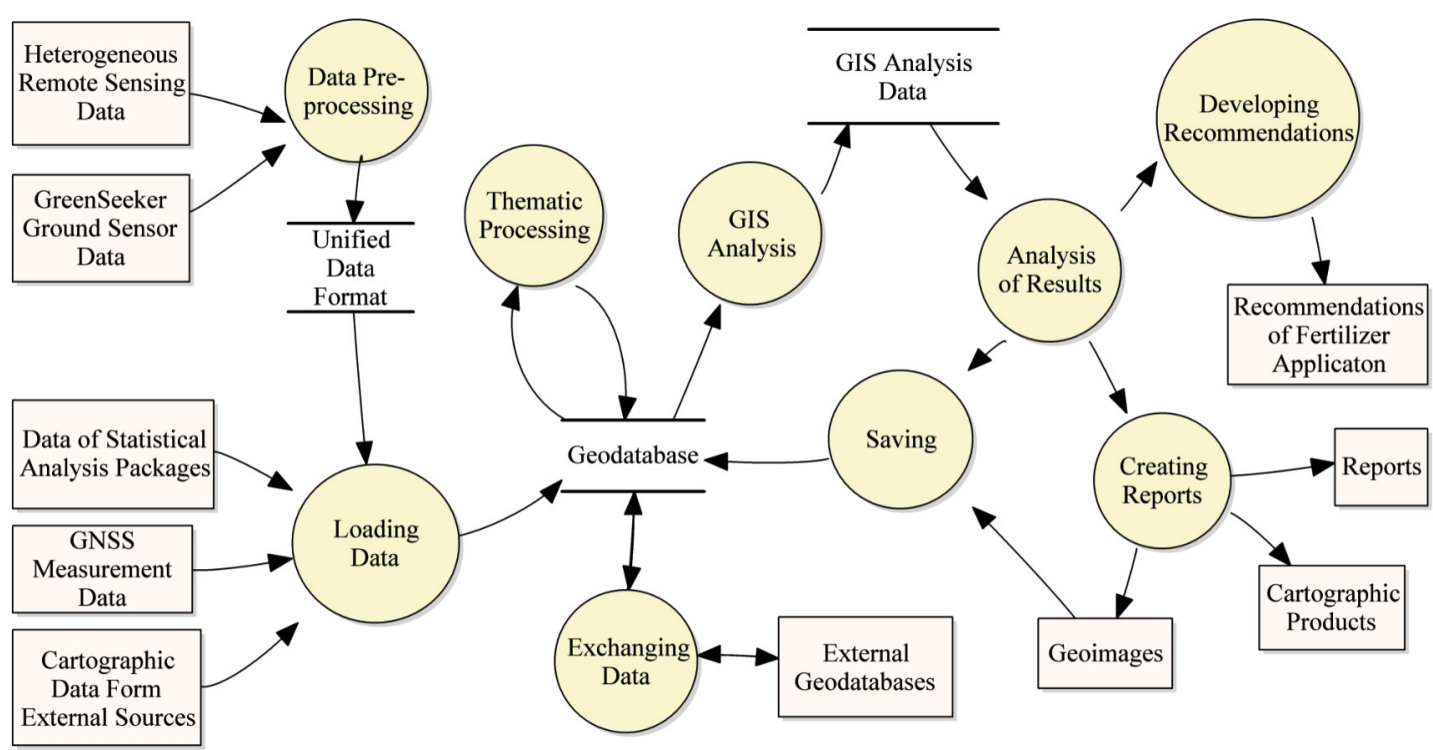

Figure 5. A Data Flow diagram for the crop monitoring system

of International Standards in the geographic information (geoinformation/geomatics) domain and INSPIRE data specification. However, despite the obvious advantages, UML is not currently widely used in software development in the area of information systems for crop monitoring.

As the example of the developed elements of crop monitoring system, a fragment of test site is presented in Figure 6. Different crop growth factors such as soil fertility, moisture content as well as the presence of hydrocarbon deposits, significantly influenced the state of winter rapeseed [Lyalko and Popov 2006].

The winter rapeseed state is based on the data from the Parrot Sequoia multi-spectrum sensor installed on UAV Disco Pro AG. Geometric correction, calibration of the outputs of the camera is based on the sunshine sensor. The thematic processing of data has been also done. Perpendicular vegetation index PVI was derived from the processed data to evaluate the healthy, diseased and damaged vegetation (Figure 6).

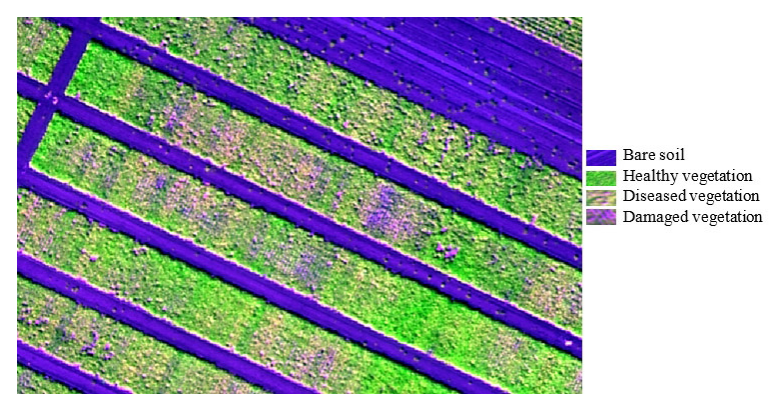

Figure 6. Test area fragment with damaged plants

\section{CONCLUSIONS}

The article presents a conceptual model as a key component of the crop monitoring system, which provides integration of heterogeneous data between the yield indicators and remote sensing data. In this study, the authors described the process of developing geodatabase models considering the construction of a set of diagrams of the Unified Modeling Language (UML). UML was used in the development of both a geoinformation crop monitoring system and the structure of the geodatabase.

It was shown that the crop monitoring system is described by the behavior of its components, which have different spatial, temporal and spectral characteristics. A set of Sequence diagrams was developed to describe the crop monitoring system. The created Data Flow diagram showed the data flow in the crop monitoring system and described the main processes involved in the functioning of the system.

\section{Acknowledgments}

Publication is funded by the Polish National Agency for Academic Exchange under the International Academic Partnerships Programme from the project "Organization of the 9th International Scientific and Technical Conference entitled Environmental Engineering, Photogrammetry, Geoinformatics - Modern Technologies and Development Perspectives". 


\section{REFERENCES}

1. Argent, R. 2004. An overview of model integration for environmental applications - components, frameworks and semantics. Environmental Modelling \& Software. 19(3), 219-234. https://doi. org/10.1016/S1364- 8152(03)00150-6

2. Atzberger, C. 2013. Advances in Remote Sensing of Agriculture: Context Description, Existing Operational Monitoring Systems and Major Information Needs. Remote Sensing. 5(2), 949-981. http:// https://doi.org/10.3390/rs5020949

3. Cucho-Padin, G., Loayza, H., Palacios, D., Balcazar, M., Carbajal, M., Quiroz, R. 2019. Development of low-cost remote sensing tools and methods for supporting smallholder agriculture. Applied Geomatics. https://doi.org/10.1007/s12518-019-00292-5

4. Filipova, O., Nikiforova, O. 2019. Definition of the Criteria for Layout of the UML Use Case Diagrams. Applied Computer Systems 24(1), 75-81. ISSN 2255-8691. https://doi.org/10.2478/ acss-2019-0010

5. Habibie, M., Noguchi, R., Shusuke, M., Ahamed, T. 2019. Land suitability analysis for maize production in Indonesia using satellite remote sensing and GISbased multicriteria decision support system. GeoJournal ,32 DOI: 10.1007/s10708-019-10091-5

6. Hyun, C., Lee, J., Lee, I. 2013. Assessment of hydrogen fluoride damage to vegetation using optical remote sensing data. In: International Society for Photogrammetry and Remote Sensing. Spatial Inf. Sci., XL-7/W2" proceedings. Antalya, Turkey. https://doi. org/10.5194/isprsarchives-XL-7-W2-115-2013

7. Jetlund, K., Onstein, E., Huang, L. 2019. Adapted Rules for UML Modelling of Geospatial Information for Model-Driven Implementation as OWL Ontologies. International Journal of Geo-Information. 8(9), 1-26. https://doi.org/10.3390/ijgi8090365

8. Khaiter, P., Erechtchoukova, M. 2019. Conceptualizing an Environmental Software Modeling Framework for Sustainable Management Using UML. Journal of Environmental Informatics. 34(2). 123-138. https:// doi:10.3808/jei.201800400

9. de Kinderen, S., Kaczmarek-Heß, M. 2019. On model-based analysis of organizational structures: an assessment of current modeling approaches and application of multi-level modeling in support of design and analysis of organizational structures". Software and Systems Modeling, (19), 19. https:// doi.org/10.1007/s10270-019-00767-4

10. Kokhan, S. and Vostokov, A. 2020. Using Vegetative Indices to Quantify Agricultural Crop Characteristics. J. Ecol. Eng., 2020. 21(4):120-127.
DOI: https://doi.org/10.12911/22998993/119808

11. Leroux, C., Jones, H., Pichon, L., Taylor, J., Tisseyre, B. 2019. Automatic harmonization of heterogeneous agronomic and environmental spatial data. Precision Agriculture, 2019. 20. 1211-1230. https:// doi.org/10.1007/s11119-019-09650-0

12. Lyalko, V. and Popov, M. 2006. Multispectral Remote Sensing in Nature Management. Naukova Dumka. Kyiv., p. 43 - 62. ISBN 966-00-0403-1 (In Ukrainian)

13. Purnamasari, R., Ahamed, T., Noguchi, R. 2018. Land suitability assessment for cassava production in Indonesia using GIS, remote sensing and multicriteria analysis. Asia-Pacific Journal of Regional Science, Springer 3(1), 1-32. http://doi: 10.1007/ s41685-018-0079-z

14. Quemada, M., Lassaletta, L., Leip, A., Jones, A., Lugato, E. 2020. Integrated management for sustainable cropping systems: Looking beyond the greenhouse balance at the field scale. Global Change Biology, https://doi.org/10.1111/gcb.14989

15. Rekha, B., Ajawan, P., Desai, V. 2018. Remote Sensing Technology and Applications in Agriculture. In: International Conference on Computational Techniques, Electronics and Mechanical Systems (CTEMS): proceedings. 193-197. Karnataka, India. http://doi. 10NN.1109/CTEMS.2018.8769124

16. Sadowska, M., Huzar, Z. 2019. Representation of UML Class Diagrams in OWL 2 on the Background of Domain Ontologies. e-Informatica Software Engineering Journal (EISEJ). 13(1), 63-103. https:// doi.10.5277/e-Inf190103

17. Stankevich, S., Shklyar, S., Lisenko, A. 2018. Prohramnyy modul' otsinky subpiksel'noho zmishchennya znimkiv, otrymuvanykh z kvadrokopteru. Ukrayins'kyy zhurnal dystantsiynoho zonduvannya Zemli. (17). 10-13. http://nbuv.gov.ua/UJRN/ ukjdzz_2018_17_4 (in Ukrainian)

18. Weiss, X., Jacobb, F., Duveillerc, G. 2020. Remote sensing for agricultural applications: A meta-review. Remote Sensing of Environment (236). https://doi. org/10.1016/j.rse.2019.111402

19. Zhai, Z., Martínez, J., Beltran, V., Martínez N. 2020. Decision support systems for agriculture 4.0: Survey and challenges". Computers and Electronics in Agriculture. 170, 16. https://doi.org/10.1016/j. compag.2020.105256

20. Zhai, C., Peterson, B., Mukhopadhyay, S. 2019. Static generation of UML sequence diagrams. International Journal on Software Tools for Technology Transfer. 23. https://doi: 10.1007/ s10009-019-00545-z 